\title{
Association Between Stress and Sexual Problems Among Married Indian Males
}

\section{REKHA ARYA ${ }^{1}$, ASHOK KUMAR PATEL ${ }^{2 *}$, NEELAM SHUKLA ${ }^{3}$ and KAVITA GUPTA ${ }^{4}$}

1Shri Vaishnav Vishwavidyalaya University, Indore, M.P., India.

${ }^{2}$ Mental Health Unit, Male District Hospital, Balrampur, U.P, India.

${ }^{3}$ S.S College Danish Kunj Kolar Rd. Bhopal M.P., India.

${ }^{4}$ Indira Gandhi Open University, Maidan Garhi, New Delhi, India.

\begin{abstract}
Background: The present study focused on the association of stress and sexual problems among married Indian Males. Stress is defined as a state of negative emotions, anxiety and insecurity which could be caused by lack of fulfillment of physical, social and psychological demands of the body that could result into negative behavioral and mental health problems. Aim: The specific objective of the study was to explore the relationship of stress and sexual problems in terms of symptom distress, social and interpersonal among 3 sample groups, viz., Psychosexually deviated, dysfunctional group and healthy subjects.

Methodology: The present associative, cross-sectional and comparative study was conducted at different hospitals located in Urban area of Indore and Nagpur with a sample size of 225 males (75 psychosexually deviated, 75 psychosexually dysfunctional, 75 psychosexually healthy married males) in the age group of 20-40 years by adminitering Outcome Questionnaire®-45.2(OQ®-45.2) developed by Dr. Michael Lambert.

Results: The study indicated that significant high symptom distress existed among psychosexually dysfunctional group as compared to the deviation and the healthy group.

Conclusion: The results showed that stress had a significant association wih Psychosexually dysfunctional group as compared to the deviation and the healthy group.
\end{abstract}



Article History

Received: 27 March 2019 Accepted: 5 August 2019

\section{Keywords}

Interpersonal Relationships; Psycho-Sexual Deviation; Psycho-Sexual Dysfunction, Symptom Distress; Social Role.

\section{Introduction}

Stress can be defined as a set of external pressures imposed on the mind and body. The body reacts to these changes with physical, mental, and emotional responses. People under large amount of stress could often experience tiredness, sickness, and

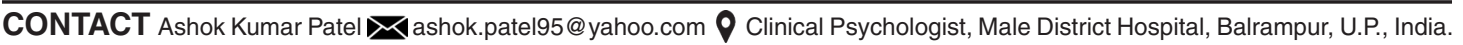
(c) (i)

(C) 2019 The Author(s). Published by Enviro Research Publishers.

This is an Open Access article licensed under a Creative Commons license: Attribution 4.0 International (CC-BY).

Doi: http://dx.doi.org/10.12944/CRJSSH.2.2.06
} 
lack of concentration. However, persistent threat particularly in older or unhealthy individuals could result in long-term effects thereby affecting health (Schneiderman 2001).

A healthy sex life and relationships contribute to physical and mental health. According to DSM III, people who have more emotional difficulties face more problems with sexual adjustment. Human sexual activity has sociological, cognitive, emotional, behavioral and biological aspects that includes personal desires, emotions, sexual drive, sexual intercourse and sexual behavior. Abnormal sexuality is defined as a behavior that is destructive to one self or others, sadistic behavior, not acceptable and painful sexual expression for partner, excludes stimulation of primary sex organs, compulsive, sex outside of marriage and various forms of sexual stimulation depending on the total context.

Sexual desire representing biological, emotional, and social health is an important aspect of the quality of life thereby playing an important role in sexual function. Research suggests that stress can indeed drive a wedge into romantic relationships. Villant (1978) reported that orthodox religious background of faster feeling of guilt and anxiety about sex could lead to psychosexual dysfunctions. Sex hormones do effect thoughts, perceptions and emotions via their influence on the brain and spinal cord (Broverman et al., 1980).

\section{- Physical Symptoms of Stress}

Physical symptoms of stress include increased heart rate, pounding heart, elevated blood pressure, sweaty palms, tightness of the chest, neck jaw and back muscles, diarrhea, constipation, urinary hesitancy, trembling, twitching, nausea, vomiting, sleep disturbances, fatigue, shallow breathing, dryness of the mouth or throat mouth, susceptibility to minor illness, cold hands, chronic pain etc.

\section{- Emotional Symptoms of Stress}

The emotional symptoms of stress include irritability, anger outburst, hostility, depression, jealousy, restlessness, withdrawl, anxiousness, diminished initiative, feeling of unreality on over-alertness, reduction of involvement of others, lack of interest, tendency to cry, being critical for others, self deprecation, nightmares, impatience, decreased perception of positive experience of opportunities, narrowed focus, obsessive rumination reduced self-esteem, insomnia, and changes in eating habits.

\section{- Cognitive Symptoms of Stress}

The Cognitive / perceptual symptoms of stress include forgetfulness, pre-occupation, blocking, blurred vision, errors in judging distance, diminished or exaggerated fantasy life, reduced creativity, lack of concentration, diminished productivity, lack of attention of detail, orientation to the past, declared psychomotor reactivity and coordination, attention deficit, disorganization of thought, negative self-esteem, diminished sense of meaning in life of control, need for too much control, negative self-statements and negative evaluation of experiences.

\section{- Behavioral Symptoms of Stress}

The behavioral symptoms of stress include increased smoking, aggressive behaviors, increased alcohol or drug use, carelessness, under-eating, over-eating compulsive behavior, maladjustment.

Till the date our society is sexually repressed and failed to accept sex as a normal function and natural need, this in turn led to inaccurate information about the sex behavior. The present study was conducted to evaluate the sexual behavior as well as, psychosexual deviation and dysfunction in order to, better understand the role of different dimension of stress with reference to sexuality.

\section{Aim}

The specific objective of the study was to explore the relationship of stress and sexual problems in terms of symptom distress, social and interpersonal among 3 sample groups, viz., Psychosexually deviated, dysfunctional group and healthy subjects.

\section{Methodology}

The present comparative, cross-sectional and associative study was conducted at different hospitals located in Urban area of Indore and Nagpur between January and July 2016. The sample size consisted of 225 male (75 psychosexually deviated, 75 psychosexually dysfunctional, 75 psychosexually 
healthy married males) in the age group of 20-40 years. This study attempted to investigate the relationship of stress with the sexual functioning of the married males in the three sample groups.

Administrative approval for the study was obtained from the head of the departments of the hospital. After obtaining formal permission from participants, the investigator explained the aims and methods of the study to all participants. Questions regarding the study were invited from the participants and they were given freedom to leave the study whenever they desire. Written informed consent was obtained before data collection. Participants were assured of the confidentiality.

\section{Tools}

The data was collected using a self-administered standardized questionnaire developed by Dr. Michael Lambert (1996) consisting of 45 questions with alpha-cronbach reliability of 0.93 . It is a newer, self-report outcome measure created and designed for repeated measurement of psychological functioning of psychotherapy patients. It has already been used in psychiatric inpatient care to evaluate symptom distress, interpersonal relationships, and social role. The $\mathrm{OQ} \mathbb{R}-45.2$ contains the three subscales:

\section{Symptom Distress}

This subscale primarily pertains to depression and anxiety.

\section{Interpersonal Relationships}

This subscale measures loneliness, conflict with others, and marriage \& family difficulties.

\section{Social Role}

This construct measures difficulties in the workplace, school, or home duties.

\section{Results}

The aim of the present investigation was to explore the relationship of stress and sexual problems in terms of symptom distress, social and interpersonal among 3 sample groups, viz., Psychosexually deviated, dysfunctional group and healthy subjects. One-way ANOVA statistical analysis was computed to analyze the difference amongst the three sample groups.

Table 1: Representation of Mean, SD and F-rations of variables in the three groups, i.e., Psychosexual deviation, Psychosexual dysfunction and Normal participants.

\begin{tabular}{|c|c|c|c|c|c|c|c|c|c|c|c|}
\hline \multirow{2}{*}{$\begin{array}{l}\text { S. no } \\
\text { Mean }\end{array}$} & \multirow{2}{*}{$\begin{array}{l}\text { Variables } \\
\text { SD }\end{array}$} & \multicolumn{2}{|c|}{$\begin{array}{l}\text { A } \\
\text { Deviation }\end{array}$} & \multicolumn{2}{|c|}{$\begin{array}{l}\text { B } \\
\text { Dysfunction }\end{array}$} & \multicolumn{2}{|c|}{$\begin{array}{l}\text { C } \\
\text { Normal F }\end{array}$} & \multirow[t]{2}{*}{ Overall } & \multirow[t]{2}{*}{$\begin{array}{l}t_{1} \\
(A: C)\end{array}$} & \multirow[t]{2}{*}{$\begin{array}{l}t_{2} \\
(B: C)\end{array}$} & \multirow[t]{2}{*}{$\begin{array}{l}t_{3} \\
(A: B)\end{array}$} \\
\hline & & Mean & SD & Mean & SD & & & & & & \\
\hline 1 & $\begin{array}{l}\text { Symptom } \\
\text { Distress }\end{array}$ & 21.39 & 2.53 & 34.99 & 2.61 & 26.08 & 1.82 & 44.525 & 24.75 & 37.77 & 13.02 \\
\hline 2 & $\begin{array}{l}\text { Interpersonal } \\
\text { Relation }\end{array}$ & 12.88 & 0.78 & 19.68 & 3.3 & 11.27 & 1.51 & 317.89 & 25.48 & 14.18 & 11.3 \\
\hline 3 & Social Role & 10.53 & 2.49 & 12.56 & 1.77 & 9.84 & 1.63 & 94.478 & 12.36 & 9.22 & 4.04 \\
\hline
\end{tabular}

From the above table, it could be elucidated that symptom distress is significantly different in the 3 groups. The t-values indicate that the dysfunction group has the highest level of symptom distress, Interpersonal Relation and social role as compared to deviation and the normal group. 


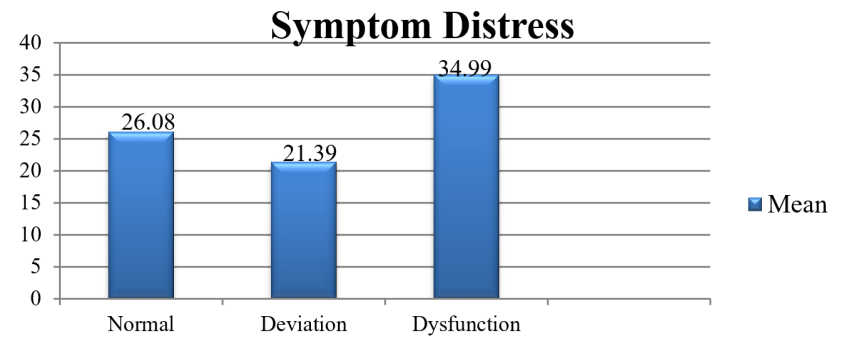

Fig. 1:Mean of Normal, Psychosexual Deviation and Dysfunctional group on Symptom Distress

\section{Interpersonal Relation}

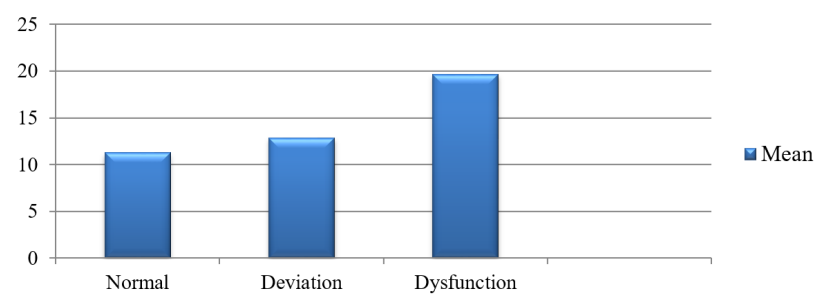

Fig. 2:Mean of Normal, Psychosexual Deviation and Dysfunctional group in Interpersonal Relation

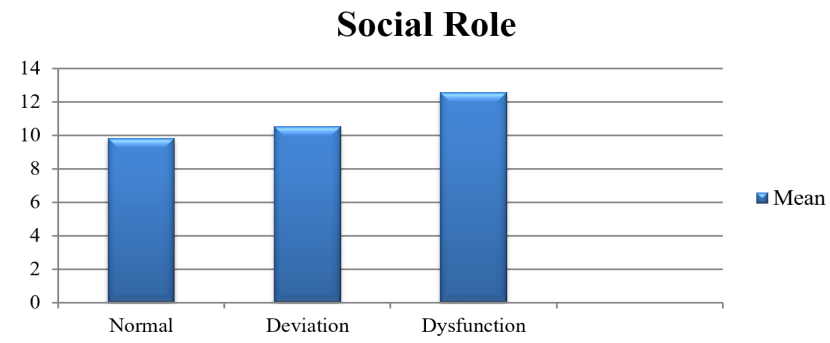

Fig. 3:Mean of Normal, Psychosexual Deviation and Dysfunctional group in Social Role

\section{Discussion}

The aim of present investigation was to explore the association of Symptoms Distress, Social Role, and Interpersonal relations of stress among psychosexually deviated (incest and pedophilia), psychosexually dysfunctional group (erectile dysfunction and premature ejaculation), and normal healthy group.

\section{Symptom Distress}

The symptom distress was found to be significantly highest in the psychosexual dysfunction group depicting that person with high score in this subscale expressed no interest in their daily activities, stressed at their work, self-blaming, thought of ending life, sadness, worthlessness, troubles, loneliness, unloved and unwanted, thought disturbance, fear of impending danger, and nervousness. In the present study, it has been observed that dysfunctional group differ significantly on symptoms distress subscale as compared to the deviation and normal group which further indicated that dysfunctional group is highly distressed. The findings of this study are consistent with a similar study where it was observed that the rate of sexual dysfunction is double in people with depression. In a study conducted, (Bodenmann et al., 2010) Stress was found to be an intermediate negative factor between sexual function and partner relationship. In another study conducted, it was observed that the incidence of organic pathology was the primary cause of psychological distress (Braak \& Braak, 1996). 
Similarly, a strong significant relatonship was observed between Premature ejaculation and high stress among the young subjects and their partners (Park et al., 2010). Similarly, in a study (Devanesan et al., 1977), it was reported that feeling of frustration, anxiety and guilt or shame was the most common feature of psychosexual dysfunction. In another study (Lambert \& Finch, 1999), it was observed that high score on symptom distress subscale indicates severity of anxious and depressive symptomatology In a similar study, it was revealed that sexual satisfaction might reduce exposure to stress, modify response to stress and promote recovery from stress (Ein-Dor and Hirschberger 2012).

\section{Interpersonal Relationship}

The dysfunctional group had a significant high score in stressful interpersonal relationship roles depicting that they are unhappy in marriage relationship, argue a lot, have unfulfilling sex life, feel unloved, unwanted and dissatisfied.

Several studies suggested that interpersonal relationship play an important role in psychosexual deviation and psychosexual dysfunction. In a study (Devanesan et al., 1977) conducted, it was reported that marital adjustment and interpersonal factors are associated with psychosexual dysfunction. According to a study (Nadelson, 1978) conducted, it was observed that disharmonious marriage is often associated with frequent arguments, feelings of loneliness and isolation that further forms the basis of possible background factor for sexual dysfunctions. In another study (Wabrek \& Wabrek, 1976) conducted, it was reported that resentments of misunderstanding between partners could aggravate psychosexual dysfunction. Previous studies conducted suggest that emotional support, openness and positive coping strategies led to lower stress levels and are subsequently correlated with better orgasm and higher sexual satisfaction while on the other hand, introversion and negative coping strategies induce high distress (Crisp et al., 2013).

\section{Social Role}

The dysfunction group had a significant high score in the stress related social role dimension indicating that the subjects did not find easy going with others, working very hard, not able to enjoy spare time, unable to concentrate on work, having difficulty with friends \& relatives, have difficulty in maintaining relationship, and mismanagement at work place, conflict, distress and inadequacy in the task related work, employment, family, roles and leisure further resulting into anxiety and stress related problems.

According to a study (Lambert and Finch, 1999) conducted, it was found that stress related to social role could result in dissatisfaction level between social and interpersonal relations. Several studies conducted illustrated that a disharmonious marriage \& family relationship and interpersonal conflicts might play a major role between significant relationships. Previous studies has established that social support benefits mental and physical health (Cohen 2004; Uchino 2004). In another study it was found that the stress disorder increased the risk of sexual dysfunction more than threefold. In another study, it was elucidated that men who were newly diagnosed with Erectile Dysfunction showed significant improvement in erectile function scores after participating in an 8-week stress management program.

\section{Conclusion}

The results indicated that psychosexually dysfunctional group had significantly high stress on symptom distress, interpersonal relations and social role as compared to the deviation and the normal group. Thus, it could be concluded that stress had a significant association with sexual dysfunction group.

\section{Limitations}

There are limited studies pertaining to sex behavior in our country. Data collection of sex behavior is a highly specialized task. On psychosexually deviated only two types of patients were included i.e., incest and pedophilia. In the area of psychosexual dysfunction, only the patients suffering from erectile dysfunction and premature ejaculation were included in the study. The other types could not be obtained for data collection since there is a large spectrum of psychosexual, deviations and dysfunctions disorders.

Moreover, the study design was cross-sectional illustrating that sexual problems increase stress 
or stress causes sexual problems. Therefore, a longitudinal study is required to address the question of causality.

\section{Acknowledgement}

We acknowledge to all the participants for their sincre participation and time devotion for the study.

\section{Funding}

The author(s) received no financial support for the research, authorship, and/or publication of this article.

\section{Conflict of Interest}

The authors declare no conflict of interest.

\section{References}

1. Bodenmann, G., Atkins, D. C., \& Scaer, M. (2010). The Association between Daily Stress and Sexual Activity. Journal of Family Psychology, 24, 271-279. http://dx.doi. org/10.1037/a0019365

2. Braak. E. \& Braak, H. (1996). Lesional patterns in Parkinson's and Alzheimer's diseases. Neuropsychology of Aging.

3. Broverman, D.M., Klaiber, E. L., \& Vogel, W. (1980). Gonadal hormones and cognitive functioning. In J.E. Parsons (ed.), The psychology of sex differences and sex roles. Washington: Hemisphere.

4. Cohen Sheldon. (2004). Social Relationships and Health. American Psychologist. ;59:676 (PubMed)(Google Scholar)

5. Crisp, C. C., Vaccaro, C. M., et al., (2013). Is Female Sexual Dysfunction Related to Personality and Coping? An Exploratory Study. Sexual Medicine, 1, 69-75. http:// dx.doi.org/10.1002/sm2.16

6. Deveanesan, M., Massler, D.J. Calderwood, M.A. and Caterini, H.R. (1977). Somatic expression of sexual anxiety. Hum Sex.

7. Ein-Dor Tsachi, Hirschberger Gilad. (2012). Sexual Healing: Daily Diary Evidence That Sex Relieves Stress for Men and Women in Satisfying Relationships. Journal of Social and Personal Relationships, 29(1): 126-139. [Google Scholar)

8. Lambert M.J., Hansen, N.B. Umphress, V., Lunnen, K. Okiishi, J. Burlingame, G. Huefner, J.C., and Reisinger, C.W. (1996). Administration and scoring manual for outcome questionnaire (OQ45-2), Wilmington, DE. American Professional credentialing services.

9. Lambert. M.J., and Finch, A.E (1999). The Outcome questionnaire. In M.E. Maruish (Ed). The use of Psychological testing of treatement planning and outcome assessment. Mahwah, NJ: Lawrence Erlbaum Associates.

10. Nadelson, C. (1978). New help for male impotence. Behaviour Med.

11. Park, H. J., Park, J. K., Park, K., et al., (2010). Prevalence of Premature Ejaculation in Young and Middle-Aged Men in Korea: A Multicenter Internet-Based Survey from the Korean Andrological Society. Asian Journal of Andrology, 12, 880-889. http://dx.doi. org/10.1038/aja.2010.9

12. Schneiderman, N., Antoni, M.H., Saab, P.G., Ironson, G. (2001). Health psychology: psychosocial and biobehavioral aspects of chronic disease management. Annu. Rev. Psychol, 52:555-580. [PubMed] [Google Scholar]

13. Uchino, Bert N. (2004). Social Support and Physical Health: Understanding the Health Consequences of Relationships. New Haven, CT: Yale University Press. [Google Scholar]

14. Villant, G.E. (1978), Natural history of male Psychological health. Correlates of successful marriage abd fatherhood Am. J. Psychaitry.

15. Wabrek, A.J. \& Wabrek, C.J. (1976), A.primer on impotence. Medical Aspects of Human sexuality. 